\title{
- UPATIONIS
}

\section{THE SOUTH AFRICAN JOURNAL OF NURSING DIE SUID-AFRIKAANSE TYDSKRIF VIR VERPLEEGKUNDIGE}

\author{
INDEX/INDEKS \\ VOLUME 8
}

MAART 1985 - DESEMBER 1985/MARCH 1985 - DECEMBER 1985

\section{SUBJECT INDEX/OPGAWE VAN ONDERWERPE}

\section{A}

Adolescence. Teenage pregnancy - a comtemporary problem of $\ldots . . . \ldots \ldots \ldots \ldots . . .$. Adolessente dogters moet voorligting oor die ondersoek van die mamma en menstruasie kry

Afdeling ses

$4(\mathrm{Dec})$

3 (Sept)

2 (Junie)

4

29

\section{B}

Behoefte van die gehospitaliseerde kleuter in opvoedingsperspektief. Die Bejaardes. Voetversorging by

Deel 1

Deel 2

Beroepskeuse van studente wat nie gekeur word nie vir generiese graadprogramme in verpleegkunde in Suid-Afrika. Die

Bestuursvaardigheidsevaluering .............

BOEKE ONTVANG/BOOKS

RECEIVED

Breastfeed or not to breastfeed? That is the question. To

Cape Town. Caring about care-givers: a study of child care workers in ................ Care-givers: a study of child care workers in Cape Town. Caring about

Caring about care-givers: a study of child care workers in Cape Town .................. Changes: ringing in the $\ldots \ldots \ldots \ldots \ldots \ldots \ldots . .$. Child care workers in Cape Town. Caring about care-givers: a study of ................ drome. A ....................................
Ciskei. Village health workers: first line of contact in the Republic of

Communication techniques for effective management. Reports and memoranda ... Community development project ........... Contraceptive methods. Factors associated with the perception of side-effects relating to the use of

Council - aspects of it's development.

The South African Nursing
3 (Sept) 20

3 (Sept) 52

4 (Des)

1 (Maart)

4 (Des)

1 (Maart) 12

3 (Sept) 47

4 (Des) 20

1 (March) 32

1 (March) 38

1 (March) 38

2(June) 9

1 (March) 38

1(March) 13

3 (Sept) $\quad 33$

2 (June) $\quad 26$

3 (Sept) 29

$3($ Sept $) \quad 45$

$4(\mathrm{Dec}) \quad 5$
2 (Junie) 25

1 (March) 38
Demographer? Why not a nurse

1 (March) 3 (Sept)

21

Development project. Community 29

E

Education for life

4 (Dec) 36

Education needs of the youth. Health .....

Education - fact or fiction. Sex

4 (Dec) 31

Effektiwiteit van verskillende leergeleenthede vir Psigiatriese Verpleegkunde studente vir die aanleer van interpersoonlike vaardighede. Die

Examinations. South African Nursing Council

4 (Dec) 24

3 (Sept) $\quad 18$

4 (Dec) 33

\section{$\mathbf{F}$}

Factors associated with the perception of side-effects relating to the use of contraceptive methods

3 (Sept) $\quad 45$

3 (Sept) 48

FOREWORD. SEE VOORWOORD

Futurologiese beskouing. 'n

1 (Maart) 35

\section{G}

Geestesvertraagde kind in die gemeenskap. Verpleging van die .................... Gehaltesorg en koste-effektiewe dienslewering deur middel van 'n geoutomatiseerde pasiënt-klassifikasiestelsel ........... Gehospitaliseerde kleuter in opvoedingsperspektief. Die behoefte van die ........... Gemeenskap. Verpleging van die geestesvertraagde kind in die ....................... Gesondheidsvoorligting — twee kulture .. Graadprogramme in Verpleegkunde in Suid-Afrika. Die beroepskeuse van studente wat nie gekeur word nie vir gene-

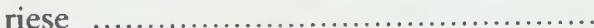
Grey`s Hospital, Pietermaritzburg - 18551985 ................................... Guillain Barré syndrome. A child in need of care
2 (Junie) 20

1 (Maart) 44

3 (Sept) $\quad 20$

2 (Junie) 20 1 (Maart) 27

1 (Maart) 10

3 (Sept) 9

1 (March) 13 
Health education needs of the youth Health services. Implications of the new regulations for psychiatric

Health Workers: First line of contact in the Republic of Ciskei. Village

$4(\mathrm{Dec})$

31

3 (Sept) 33

Implications of the new regulations for psychiatric health services Implications of the new regulations for the Universities. The

3 (June) 16

2 (June)

4 (Dec)

Inservice training in nursing

Interpersoonlike vaardighede. Die effektiwiteit van verskillende leergeleenthede vir die aanleer van .......................... Intra partum foetal distress

$3($ Sept)

$3($ Sept)

3 (Sept)

18

48

48

K

Kaapstad. 'n Ondersoek na faktore wat met kontraseptiewe staking verband hou: Kleurlingvroue in die metropolitaanse gebied van

Kleurlingvroue in die metropolitaanse gebied van Kaapstad. "n Ondersoek na faktore wat met kontraseptiewe staking verband hou:

Kleuter in opvoedingsperspektief. Die behoeftes van die gehospitaliseerde ..........

Kliniese onderrig: dis makliker as wat u dink!

Kontraseptiewe staking verband hou: Kleurlingvroue in die metropolitaanse gebied van Kaapstad. 'n Ondersoek na faktore wat met

Koste-effektiewe dienslewering deur middel van 'n geoutomatiseerde pasiënteklassifikasiestelsel. Rekenaars in verpleegkunde Deel 3. Gehaltesorg en ........ Kulture. Gesondheidsvoorligting. Twee .

\section{$\mathbf{L}$}

Leergeleenthede vir Psigiatriese Verpleegkunde studente vir die aanleer van interpersoonlike vaardighede. Die effektiwiteit van verskillende Lyding

2 (Junie) $\quad 44$

2(Junie) 44

3 (Sept) 20

2 (Junie) $\quad 30$

2 (Junie) 44

1 (Maart) 44

1 (Maart) 27

3 (Sept)

18

2 (Junie)
2(June) 16 Psigiatriese Verpleegkunde studente vir

Nurse demographer? Why not a

Nurse managers for informed action. Pre-

paring

Nursing Council - aspects of it's development. The South African ............. Nursing. Inservice training in $\ldots \ldots \ldots \ldots \ldots$

Nursing is the concern of all citizens ........ Nursing student at the University of South Africa. The

\section{0}

Ondersoek na faktore wat met kontraseptiewe staking verband hou: Kleurlingvroue in die metropolitaanse gebied van Kaapstad. 'n

2(Junie)

44

Onderrig: Dis makliker as wat u dink. Kliniese

Opmerkings oor 'n ondersoek na die tekort van verpleegpersoneel in Transvaalse Provinsiale Hospitale, 1983

Opvoedingsperspektief. Die behoeftes van die gehospitaliseerde kleuter in

1(March)

21

3 (Sept) $\quad 15$

$4(\mathrm{Dec}) \quad 5$

4 (Dec) 48

2 (June) 4

1 (March) 4

2 (Junie) $\quad 30$

1 (Maart) 16

3(Sept) $\quad 20$

Pasiëntklassifikasiestelsel. Rekenaars in verpleegkunde - Deel 3. Gehaltesorg en koste-effektiewe dienslewering deur middel van 'n geoutomatiseerde ............. Performance. Predictors of student nurse Predictors of student nurse performance .. Pregnancy - a contemporary problem of adolescence. Teenage

Preparing nurse managers for informed action ..................................... Psigiatriese Verpleegkunde studente. Die effektiwiteit van verskillende leergeleenthede vir die aanleer van interpersoonlike vaardighede

$3(\operatorname{Sept})$

18

1 (Maart) 44

2(June) 47

2 (June) 47

$4(\mathrm{Dec}) \quad 21$

$3(\operatorname{Sept}) \quad 15$

\section{R}

Regulations for psychiatric health services. Implications of the new ..................... Regulations for the Universities. The implications of the new ........................

Mamma en menstruasie kry. Adolessente dogters moet voorligting oor die ondersoek van die

Management. Reports and memoranda Communication techniques for effective. Managers for informed action. Preparing nurse

3 (Sept) 4 Rekenaars in verpleegkunde - Deel 3. Gehaltesorg en koste-effektiewe diensle2 (June) $26 \quad$ wering deur middel van 'n geoutomatiseerde pasiëntklassifikasiestelsel ............ Rekenaars in verpleegkunde - Deel 4 . 'n Rekenaargesteunde wissellys .............. Reports and memoranda. Communication techniques for effective management ..... Ringing in the changes ......................
2 (June) $\quad 16$

2(June) 13

1 (Maart) 44

2 (Junie) $\quad 50$

2 (June) $\quad 26$

2 (June) 9

3 (Sept) $\quad 38$ mamma en

Rouproses. Die 
Sex education - fact or fiction

Side-effects relating to the use of contraceptive methods. Factors associated with the perception of

Singapore - The nursing scene

Skoolverpleging - 'n voorligtingsuitdaging .......................................

South African Nursing Council-aspects of it's development. The

South African Nursing Council examinations

South Africa. The Nursing student at the University of

Spina Bifida. A descriptive research study Student at the University of South Africa.

The nursing

Student nurse performance. Predictors of

Studente vir die aanleer van interpersoonlike vaardighede. Die effektiwiteit van verskillende leergeleenthede vir psigiatriese verpleegkunde

Studente wat nie gekeur word nie vir generiese graadprogramme in Verpleegkunde in die Republiek van Suid-Afrika. Die beroepskeuse van

T

Teenage pregnancy - a contemporary problem of adolescence .................... To breastfeed or not to breastfeed? That is

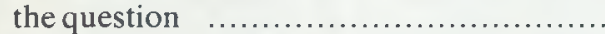
Transvaalse Provinsiale Hospitale, 1983. Opmerkings oor ' $n$ ondersoek na die tekort aan verpleegpersoneel in

\section{U}

Universities. The implications of the new regulations for the University of South Africa. The nursing student at the

$\begin{array}{lr}4 \text { (Dec) } & 24 \\ 3 \text { (Sept) } & 45 \\ 1 \text { (March) } & 49 \\ 2 \text { (Junie) } & 24 \\ 4 \text { (Dec) } & 5 \\ 4 \text { (Dec) } & 33 \\ 1 \text { (March) } & 4 \\ 2 \text { (June) } & 36 \\ 1 \text { (March) } & 4 \\ 2 \text { (June) } & 47 \\ & \\ 3 \text { (Sept) } & 18 \\ & \\ 1 \text { (Maart) } & 10 \\ & \\ \end{array}$

$4(\mathrm{Dec}) \quad 21$

1 (March) 32

1 (Maart) 16

Why not a nurse demographer?

Wissellys. Rekenaars in verpleegkunde Deel 4. 'n Rekenaargesteunde

1 (March)

2(Junie)

50

2(June) 13

1 (March) 4

Vaardighede. Die effektiwiteit van verskillende leergeleenthede vir Psigiatriese Verpleegkunde studente vir die aanleer van in-

Verlede as eerste behandeling. Die ......... Verpleegkunde in die Republiek van SuidAfrika. Die beroepskeuse van studente wat nie gekeur word nie vir generiese Vraadprogramme in .......................... siale Hospitale, 1983. Opmerkings oor 'n ondersoek na die tekort aan $. . . . . . \ldots \ldots \ldots . . .$. Verpleging van die geestesvertraagde kind VIGS. Implikasies vir SA Verpleegkun-

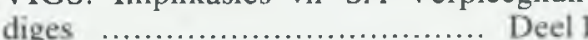

Village health workers. First line of contact in the Republic of Ciskei

Deel 1

Deel 2

Voorligting oor die ondersoek van die mamma en menstruasie kry. Adolessente Voorligtingsuitdaging. Skoolverpleging 'n

VOORWOORD/FOREWORD ............

e) 23

1 (Maart) 3

2(Junie) 3

3 (Sept) 3

4 (Des) 3

\section{W}

3 (Sept) 18

1 (Maart) 16

2 (Junie) 20

3 (Sept) 13

3 (Sept) 33

4 (Des)

40

4

3

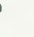




\section{OPGAWE VAN SKRYWERS/INDEX OF AUTHORS}

A

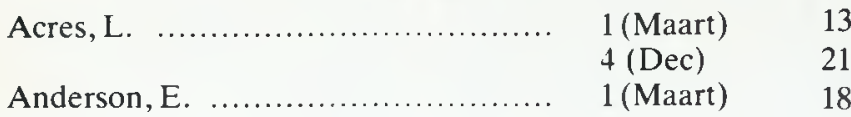

B

Basson, A.

Block, S.C.

3 (Sept)

1 (Maart)

2(Junie)

1 (Maart)

3 (Sept)

4 (Dec)

1 (Maart)

Brownlee, E.B.I.

2(Junie)

C

Cilliers, F.

Coertse, E.

Coetsee. M

Coetsee, $M$

Coetzee, $\mathrm{H}$

Coetzer, P.W.W.

4 (Dec)

1 (Maart)

1 (Maart)

2 (Junie)

2(Junie)

1 (Maart)

D

De Jong, $\mathrm{V}$.

De Villiers, $F$.

De Villiers, $F$.

Doyle, M.A.

Duckworth. J.G.

4 (Dec)

2(Junie)

3 (Sept)

1 (Maart)

3(Sept)

E

Elk, R

Erasmus, G

1 (Maart) 38

3(Sept) $\quad 45$

F

Ferreira, A

3 (Sept)

H

Hall, E.J.

Herbst, M.C.

1 (Maart)

3 (Sept)

4 (Dec)

K

Kotzé, W.J.

Kubheka, J

3 (Sept)

L

Labuschagne, $\mathrm{L}$.

4 (Des)

Lephadi, M.
$4(\mathrm{Dec})$
Mbawa, E.

Mearns, P.C.

Menyatso, G.P.

Moir, A.E.A

Mokoena, A

Monaheng, C

Moolman, S.J.

Mosisidie, $\mathrm{M}$.

Mostert, S.J.

Mulaudzi, F

Muller, M

Myburgh, J.

3 (Sept)

2 (Junie)

1 (Maart)

2(Junie)

3 (Sept)

3 (Sept)

2 (Junie)

1 (Maart)

3 (Sept)

3 (Sept)

4 (Dec)

1 (Maart)

\section{$\mathbf{N}$}

Ngetu, Z

Nomtuli, G.

3 (Sept)

4 (Des)

48

48

Nolte, A.

\section{0}

Oelofse, L.

4 (Des)

48

47

23

48

48

21

45

48

48
32

48

15
3 (Sept)

Parsons, C.R

2 (Maart) 26

Paverd, N.V.

2 (Junie)

Peters, E.

Petersen, G.A

3 (Sept)

Poggenpoel, $\mathrm{M}$

1 (Maart)

Potgieter, $\mathrm{M}$

4 (Des)

Potgieter, S

4 (Des)

4 (Des)

Powell, C.

4 (Des)

Price, S

1 (Maart)

Professional Section, SA Nursing Council (4 Dec)

R

Rautenbach, C.

2(Sept)

Robertson, B

2 (Sept)

33

$\mathbf{S}$

Scheepers, S.D.

1 (Maart)

2(Junie)

Simpson, M.A.

Strydom, M.

4 (Dec)

2 (Junie)

Swart, M.

4 (Dec) 53

U

Uys, L.R

1 (Maart) 10

Uys, L.R.

3 (Sept)

18
48

48
Majola, V.

Makwakwa, C.M

3 (Sept)

48

38

48

48

48

48

32
33

3

(1)

2(Junie) $\quad 30$

2(Junie) 29

2(Junie) 30

3(Sept) 29

3 (Sept) 29

3 (Sept) 52

4 (Des) 40
3 (Sept) 4 